\title{
NOMENCLATURAS DE ESPECTROMETRIA DE MASSAS EM LÍNGUA PORTUGUESA
}

\section{Ricardo Vessecchi e Norberto Peporine Lopes*}

Departamento de Física e Química, Faculdade de Ciências Farmacêuticas de Ribeirão Preto, Universidade de São Paulo, Av. do Café, s/n, 14040-903 Ribeirão Preto - SP, Brasil

\section{Fábio Cesar Gozzo}

Instituto de Química, Universidade Estadual de Campinas, CP 6154, 13083-970 Campinas - SP, Brasil

Felipe Augusto Dörr

Faculdade de Ciências Farmacêuticas, Universidade de São Paulo, Av. Prof. Lineu Prestes, 580, 05508-900 São Paulo - SP, Brasil

Michael Murgu

Waters Corporation, Al. Tocantins, 125, 27 andar, 06455-020 Barueri - SP, Brasil

Daniel Temponi Lebre

Centro de Espectrometria de Massas Aplicada Ltda., Instituto de Pesquisas Energéticas e Nucleares/CIETEC, Av. Prof. Lineu Prestes, 2242, 05508-000 São Paulo - SP, Brasil

\section{Renato Abreu}

Agilent Technologies Brasil, Al. Araguaia, 1142, $1^{\circ}$ andar, 06455-020 Barueri - SP, Brasil

\section{Oscar Vega Bustillos}

Instituto de Pesquisas Energéticas e Nucleares, Av. Prof. Lineu Prestes, 2242, 05508-000 São Paulo - SP, Brasil

José Manuel Riveros

Instituto de Química, Universidade de São Paulo, CP 26077, 05599-970 São Paulo - SP / Centro de Ciências Naturais e Humanas, Universidade Federal do ABC, Av. dos Estados, 5001, 09210-971 Santo André - SP, Brasil

Recebido em 24/8/11; aceito em 29/8/11; publicado na web em 30/9/11

MASS SPECTROMETRY NOMENCLATURE IN PORTUGUESE LANGUAGE. In commemoration of the International Year of Chemistry this article presents the normalization and standardization of key terms used in mass spectrometry in Portuguese Language.

Keywords: mass spectrometry; nomenclature; Portuguese language.

\section{INTRODUÇÃO}

O Ano Internacional da Química (AIQ), em 2011, tem sido celebrado através de diferentes ações. Os colegas, durante este ano, já perceberam o resultado dessa iniciativa tomada na $63^{\text {a }}$ Sessão da Assembleia Geral da ONU, que visa celebrar a contribuição da Química para a humanidade, com o lema Chemistry - our life, our future. Além da esperada reflexão sobre o estado da arte na Química, as sociedades científicas estão atuando na organização de eventos de grande porte com fóruns internacionais, em ações de divulgação como feiras de ciências e mídia, em ações educativas como confecção de materiais didáticos para o ensino médio, entre outras. Nesse contexto, o Presidente da Sociedade Internacional de Espectrometria de Massas, um dos organizadores do compêndio de nomenclatura na área junto à IUPAC, indicou a membros da Sociedade Brasileira de Espectrometria de Massas e da Sociedade Brasileira de Química que organizassem um material didático sobre o tema em língua portuguesa. O material compilado faz uma adaptação para nossa língua dos termos e definições usados de forma corrente em espectrometria de massas. Para isso, sugerimos a leitura das referências que se encontram no final desse texto, ${ }^{1-11}$ onde estão as definições em língua inglesa, com os créditos aos autores pioneiros, que compilaram as terminologias originais. Esperamos que esse material educativo auxilie o grande número de pesquisadores, professores e estudantes que atuam na área

*e-mail: npelopes@fcfrp.usp.br e que, assim, possamos ter uma comunicação em espectrometria de massas mais eficiente em nosso idioma.

\section{TERMOS EM ORDEM ALFABÉTICA}

\section{Ablação por laser - laser ablation}

Remoção de material de uma amostra sólida ou líquida, através de energia fornecida por um laser de pulso curto para formar espécies em fase gasosa e partículas.

Abundância isotópica natural - natural isotopic abundance

A abundância isotópica de um elemento da maneira como encontrado na natureza.

Afinidade eletrônica (AE) - electron affinity (EA)

Energia mínima necessária para a formação de uma espécie neutra a partir de um ânion radical pelo processo $\mathrm{M}^{-} \rightarrow \mathrm{M}+\mathrm{e}^{-}$, onde $\mathrm{M}^{-}$e $\mathrm{M}$ estão em seus estados fundamentais eletrônicos, de energia vibracional e rotacional, e o elétron possui energia translacional nula. Convencionalmente, a afinidade eletrônica é descrita como a energia liberada pelo processo $\mathrm{M}+\mathrm{e}^{-} \rightarrow \mathrm{M}^{-}$.

Afinidade protônica (AP) - proton affinity (PA)

Para uma dada espécie M, é o negativo da variação de entalpia para a reação de protonação em fase gasosa a $298 \mathrm{~K}$ do tipo $\mathrm{M}+\mathrm{H}^{+} \rightarrow[\mathrm{M}+\mathrm{H}]^{+}$.

Agregado iônico - ion cluster

Um íon formado pela combinação, por interações não covalentes, de dois ou mais átomos ou moléculas de uma ou mais espécies quí- 
micas, tais como $\left[\left(\mathrm{H}_{2} \mathrm{O}\right)_{n} \mathrm{H}\right]^{+},\left[(\mathrm{NaCl})_{n} \mathrm{Na}\right]^{+}$ou $\left[\mathrm{M}+\mathrm{Na}+\mathrm{CH}_{3} \mathrm{OH}\right]^{+}$, onde $\mathrm{M}$ representa uma molécula.

Altura do sinal - peak height

A altura do sinal registrado em um espectro de massa.

Analisador de energia eletrostática ou setor elétrico - electrostatic energy analyzer (ESA)

Dispositivo composto por um par de placas condutoras paralelas, cilindros concêntricos ou esferas concêntricas, capaz de separar partículas carregadas de acordo com a razão entre sua energia translacional e sua carga, por meio de uma diferença de potencial aplicada entre o par de elementos.

Análise da razão de isótopos estáveis em aminoácidos em cultura de células - stable isotope ratio analysis of amino acids in cell culture (SILAC)

Técnica de proteômica para detectar diferenças na abundância de proteínas entre amostras de cultura de células por meio da marcação isotópica de proteínas. A marcação com isótopos estáveis é obtida pelo fornecimento de aminoácidos isotopicamente enriquecidos a uma cultura de células, e aminoácidos naturais para a cultura a ser comparada.

Análise de íons produto - product ion analysis

Processo pelo qual um íon precursor de uma $\mathrm{m} / \mathrm{z}$ particular é selecionado, sua fragmentação é induzida, e o espectro de massas dos íons produto resultantes é registrado.

Análise de massas - mass analysis

Processo pelo qual uma mistura de espécies iônicas ou neutras é identificada de acordo com suas $\mathrm{m} / \mathrm{z}$ (íons) ou pelas massas atômicas agregadas (espécies neutras). A análise pode ser quantitativa ou qualitativa.

Equivalentes de ligações duplas e anéis - rings plus double bonds, ring and double bond equivalent

Medida do grau de insaturação de uma molécula orgânica dada por $\mathrm{X}-\mathrm{Y} / 2+\mathrm{Z} / 2+1$, onde $\mathrm{X}$ é o número de átomos de carbono, $\mathrm{Y}$ é o número de átomos de hidrogênio ou de halogênio e $\mathrm{Z}$ é o número de átomos de nitrogênio e fósforo.

Aquisição centroide - centroid acquisition

Procedimento de aquisição de espectros de massas no qual um sistema computadorizado detecta os picos, calcula sua centroide considerando o valor médio da $\mathrm{m} / \mathrm{z}$ ponderado pela intensidade de cada pico, e atribui valores de $\mathrm{m} / \mathrm{z}$ com base em um arquivo de calibração. Apenas os valores centroides de $\mathrm{m} / \mathrm{z}$ e a magnitude do pico são arquivados.

Aquisição dependente de dados - data dependent acquisition

Modo de aquisição de dados em espectrometria de massas sequencial na qual um número determinado de picos é selecionado em um espectro de varredura, usando regras pré-determinadas, para um segundo experimento de espectrometria de massas sequencial.

Aquisição no modo perfil - profile mode

Método para aquisição de dados em espectrometria de massas onde cada pico é registrado como uma curva gaussiana, onde cada ponto na curva corresponde à intensidade de sinal naquele valor específico de $m / z$.

\section{Armadilha de íons de Kingdon - Kingdon trap}

Um dispositivo de captura de íons que consiste de um eletrodo externo do tipo barril e um eletrodo interno coaxial fusiforme, os quais formam um campo eletrostático com potencial de distribuição quadro-logarítmica. A frequência das oscilações harmônicas dos íons presos em órbita ao longo do eixo do campo eletrostático é independente da velocidade do íon, porém inversamente proporcional à raiz quadrada da $\mathrm{m} / \mathrm{z}$, de modo que a armadilha pode ser operada como um analisador de massas, utilizando a detecção da imagem da corrente e a transformada de Fourier do sinal no domínio do tempo.

Nota: O termo Orbitrap (marca registrada) tem sido usado para descrever uma armadilha de Kingdon quando utilizada em um espectrômetro de massas.

Armadilha de íons de Paul, ion trap de Paul - Paul ion trap, storage trap, quadrupole ion trap

Dispositivo de captura de íons que depende da aplicação de tensões de radiofrequência entre um eletrodo anelar e dois eletrodos terminais para limitar o movimento dos íons a um caminho cíclico descrito por uma forma apropriada da equação de Mathieu. A escolha destas tensões determina a $\mathrm{m} / \mathrm{z}$ abaixo da qual os íons não são aprisionados.

Armadilha de íons de Penning, ion trap de Penning - Penning ion trap

Dispositivo de captura de íons utilizando um campo magnético estático e um potencial elétrico estático circular. O campo magnético limita o movimento dos íons a órbitas circulares em torno da direção da linha de força magnética, que se alinha com a direção do eixo de captura, enquanto o potencial elétrico circular confina o movimento axial dos íons. Este dispositivo é utilizado em espectrômetros de massas de ressonância ciclotrônica de íons com transformada de Fourier.

Armadilha de íons, ion trap - ion trap

Dispositivo capaz de confinar espacialmente íons pelo uso de campos elétricos ou magnéticos isolados ou em associação.

Armadilha de íons linear - linear ion trap

Armadilha de íons bidimensional do tipo Paul, na qual os íons são confinados na dimensão axial aplicando um potencial elétrico estático.

Ativação colisional ou excitação colisional - collisional activation, collisional excitation

Interação de um íon com outra espécie em fase gasosa, usualmente um gás inerte, na qual parte da energia translacional relativa dos compostos em interação é convertida em energia interna. $\mathrm{O}$ aumento na energia interna de um íon pode resultar na sua fragmentação.

Autodestacamento - autodetachment

Processo pelo qual um íon negativo em um estado energético distinto, com energia maior que a energia mínima necessária para perder um elétron espontaneamente, sem interação adicional com uma fonte de energia.

\section{Autoionização - autoionization}

Formação de um íon quando um átomo ou molécula, em um estado distinto com energia interna maior que a energia mínima de ionização, perde um elétron espontaneamente, sem interação adicional com uma fonte de energia.

Axialização - axialization

Técnica utilizada na espectrometria de massas por ressonância ciclotrônica de íons com transformada de Fourier. Serve para reduzir a movimentação dos íons de maneira a concentrá-los em um pequeno espaço próximo ao centro do analisador, aumentando assim critérios de desempenho, como poder de resolução.

Biblioteca de espectros de massas - mass spectral library

Uma coleção de espectros de massas de diferentes compostos.

Bombardeamento por íons rápidos - fast ion bombardment (FIB)

Ionização de qualquer espécie pela interação de um feixe focalizado de íons, que têm uma energia translacional de vários $\mathrm{keV}$, com uma amostra sólida ou líquida.

Calibração de massa - mass calibration

Um método para determinar os valores de $\mathrm{m} / \mathrm{z}$ dos íons a partir de sinais experimentais usando uma equação teórica ou empírica. Normalmente isto é feito usando-se um sistema computadorizado e um arquivo de calibração obtido de um espectro de massas de um composto que gera íons de $\mathrm{m} / \mathrm{z}$ conhecidos.

Capilar de eletrospray - electrospray capillary, electrospray needle, electrospray emitter

Capilar de pequeno diâmetro interno utilizado para nebulização 
e emissão de gotículas altamente carregadas durante ionização por electrospray.

Captura de elétrons dissociativa - dissociative electron capture

Mecanismo de ionização onde a captura de um elétron de baixa energia por uma molécula leva diretamente à dissociação do íon gerado. É um exemplo de ionização dissociativa.

Cátion alila - allyl cation

Um íon de camada fechada (elétron-par), descrito como $R^{1} R^{2} C=C^{3}-C^{+} R^{4} R^{5}$ e suas possíveis formas de ressonância.

Cátion alquila - alkyl cátion

Um íon de camada fechada (elétron-par) formado por hidrocarbonetos saturados, sem a presença de grupos aromáticos. É um caso especial de íons carbênio.

Célula de colisão, câmara de colisão - collision cell

Câmara localizada entre a região de aceleração de íons na fonte e o primeiro analisador de massas, ou entre analisadores de massa em equipamentos de espectrometria de massas sequencial no espaço. Este ambiente pode ser preenchido com um gás de colisão para ativação colisional em experimentos de dissociação induzida por colisão.

Célula reacional de colisão - collision reaction cell

Célula de colisão para a remoção de íons interferentes através de reações íon/espécie neutra na espectrometria de massas por plasma indutivamente acoplado (ICP-MS).

Clivagem alfa - alfa cleavage

Cisão homolítica onde o rompimento da ligação ocorre entre um átomo adjacente ao átomo do sítio de carga aparente e um átomo distante do sítio de carga aparente por duas ligações.

Clivagem beta - beta cleavage

Cisão homolítica onde o rompimento da ligação ocorre entre um átomo distante do sítio de carga aparente por duas ligações e um átomo vizinho, o qual está distante do sítio de carga aparente por três ligações.

Coletor de íons - ion collector

Dispositivo para capturar determinados íons, como um copo de Faraday ou uma multiplicadora de elétrons.

Compostos ônio - onium compounds

Cátions obtidos pela adição de $\mathrm{H}^{+}$a um hidreto de um elemento da família do nitrogênio, dos calcogênios ou dos halogêneos como, por exemplo, $\left(\mathrm{NH}_{4}^{+}\right)$amônio, $\left(\mathrm{H}_{3} \mathrm{O}^{+}\right)$oxônio (hidrônio) $\left(\mathrm{H}_{2} \mathrm{~F}^{+}\right)$fluoronônio, etc.

Cone de Taylor - Taylor cone

Formato cônico do líquido saindo de um capilar sobre alta voltagem como em electrospray ou outro processo de spray eletroidrodinâmico.

Contraeletrodo - counter electrode

Em uma fonte de ionização por electrospray, o contraeletrodo é um dos dois eletrodos entre os quais a alta tensão é aplicada, sendo o capilar do electrospray o outro eletrodo.

Corrente iônica total - total ion current (TIC)

Somatório de todas as correntes iônicas individuais produzidas por íons de diferentes $\mathrm{m} / \mathrm{z}$ presentes em um espectro de massas ou em uma faixa de específica de $\mathrm{m} / \mathrm{z}$ em um espectro de massas.

Cromatografia de fluído supercrítico/espectrometria de massas - supercritical fluid chromatography/mass spectrometry (SFC/MS)

Técnica combinada na qual uma mistura de analitos é separada em soluções de componentes individuais por cromatografia de fluído supercrítico, seguida pela ionização do efluente na fonte de um espectrômetro de massas.

Cromatografia em fase gasosa/espectrometria de massas (CG/ EM) - gas chromatography/mass spectrometry (GC/MS)

Técnica na qual uma mistura de compostos é separada em componentes individuais por cromatografia em fase gasosa, sendo o efluente da separação ionizado na fonte de íons do espectrômetro de massas.
Nota: Não há consenso sobre o uso de uma barra ou hífen nesta sigla.

Cromatografia líquida/espectrometria de massas - liquid chromatography/mass spectrometry (LC/MS)

Técnica na qual uma mistura de compostos é separada em componentes individuais por cromatografia líquida, sendo o efluente da separação ionizado na fonte de íons do espectrômetro de massas.

Nota: Não há consenso sobre o uso de uma barra ou hífen nesta sigla.

Cromatograma de íon extraído - extracted ion chromatogram

Cromatograma criado pelo registro da intensidade do sinal observado para um determinado valor ou conjunto de valores de $\mathrm{m} / \mathrm{z}$, em uma série de espectros de massas gravados em função do tempo de retenção.

Cromatograma de íons totais - total ion chromatogram (TIC)

Cromatograma obtido pelo somatório (total) da intensidade de sinais de íons em cada um dos espectros de massas de uma série adquirida em função do tempo de retenção cromatográfico.

Nota: Não se deve confundir a sigla TIC com corrente iônica total.

Cromatograma do pico base - base peak chromatogram (BPC)

Cromatograma obtido pela representação gráfica da intensidade absoluta do pico base em cada espectro de massas obtido em uma série de medidas, em função do tempo de retenção.

Nota: este termo se aplica a amostras introduzidas após separação cromatográfica.

Dalton, Da

Unidade de massa não pertencente ao SI e que é numericamente idêntica à unidade de massa atômica unificada (símbolo $u$ ).

Decaimento pós-fonte - post-source decay (PSD)

Técnica específica para espectrômetros de massas com analisadores por tempo de voo com refletor. Os íons produto gerados por íons metaestáveis, quando formados antes de sua passagem pelo refletor, podem ser separados de acordo com sua $\mathrm{m} / \mathrm{z}$ para gerar um espectro de íons produto.

Defeito de massa - mass defect

Diferença entre o número inteiro de massa e a massa monoisotópica de um átomo, molécula ou íon.

Derivação para inserção de carga - charge site derivatization

Derivatização química de moléculas para introdução de cargas fixas, como aminas quaternárias ou íons fosfônio, visando aumentar a eficiência de ionização em eletrospray ou em dessorção a laser assistida por matriz (MALDI) e direcionar a fragmentação para obtenção de íons produto mais informativos acerca da molécula em questão.

Descarga corona - corona discharge

Descarga elétrica gerada em um gás, normalmente a pressão atmosférica, o qual circunda um condutor com um potencial elétrico suficientemente elevado para que o campo elétrico ao seu redor seja capaz de ionizar o gás. Como resultado, um plasma é formado na proximidade do condutor, porém sem a formação de arco voltaico.

Dessolvatação de íons - ion desolvation

Remoção de moléculas de solvente agregadas a um íon em fase gasosa, por meio de aquecimento e/ou colisões com moléculas de um gás.

\section{Dessorção por campo - field desorption (FD)}

Formação de íons em fase gasosa a partir de um material depositado em uma superfície sólida, conhecida como "emissor", na presença de um campo elétrico. Uma vez que este processo provavelmente envolve outros mecanismos de ionização além da ionização por campo, o termo "dessorção por campo" não é preciso, apesar de seu grande uso. 
Dessorção/ionização a laser auxiliada por matriz - matrixassisted laser desorption/ionization (MALDI)

Formação de íons em fase gasosa a partir de moléculas presentes em uma matriz sólida ou líquida, a qual é irradiada com um laser. A matriz é um material que absorve a energia do laser e auxilia a ionização.

Dessorção/ionização em plasma - plasma desorption/ionization

A ionização do material em uma amostra sólida pelo bombardeamento desta com íons e/ou átomos neutros formados como resultado da fissão de um nuclídeo adequado, tipicamente ${ }^{252} \mathrm{Cf}$.

Dessorção/ionização por laser - laser desorption/ionization (LID)

Formação de espécies em fase gasosa a partir da superfície de uma amostra sólida ou líquida após ativação por um feixe de fótons de um laser.

Detector de conversão de íons em fótons - ion-to-photon detector

Detector no qual os íons colidem com um dinodo de conversão para gerar elétrons que, por sua vez, colidem com uma substância fosforescente, liberando fótons que são detectados por uma fotomultiplicadora.

Diagrama de estabilidade de Mathieu - Mathieu stability diagram

Uma representação gráfica expressa em termos de coordenadas adimensionais que descreve a estabilidade ou instabilidade do movimento de partículas carregadas em um espectrômetro de massas de transmissão quadrupolar ou em um ion trap de Paul, tendo como base uma forma apropriada da equação diferencial de Mathieu.

Dinodo de conversão - conversion dynode

Superfície mantida em alta tensão a fim de que íons que colidam com essa superfície produzam partículas secundárias com carga, que são posteriormente detectadas.

Nota: para íons positivos, a tensão é negativa e as partículas secundárias são elétrons e íons negativos. Para íons negativos, a tensão é positiva e as partículas secundárias são íons positivos.

Dinodo multiplicador de partículas contínuo, multiplicadora de elétrons - continuous dynode particle multiplier

Um detector que transforma íons em elétrons através do impacto destes na superfície interna de um tubo contínuo, induzindo a produção de elétrons secundários. Estes elétrons, por sua vez, também atingem a superfície interna do tubo, produzindo mais elétrons secundários. Este efeito de avalanche amplifica o sinal e produz um aumento na medida final do pulso de corrente.

Dinodo multiplicador de partículas descontínuo - discrete dynode particle multiplier

Um detector que transforma íons em elétrons através do impacto destes na superfície de um eletrodo, induzindo a produção de elétrons secundários. Estes elétrons, por sua vez, atingem sequencialmente outros dinodos carregados com um potencial elétrico mais positivo, o que leva à produção de mais elétrons secundários. Este efeito de avalanche amplifica o sinal e produz um aumento na medida final do pulso de corrente.

Dissociação induzida por colisão - collision-induced dissociation (CID), collisionally activated dissociation (CAD)

Dissociação de um íon após sua excitação ou ativação colisional. Neste processo, a energia interna do íon, aumentada pela colisão com um gás inerte, é dissipada por meio de sua fragmentação.

Dissociação induzida por colisão na fonte de ionização - insource collision-induced dissociation

Dissociação de um íon após excitação colisional durante sua transferência da região de pressão atmosférica na fonte de ionização para a região de vácuo do espectrômetro de massas. Este processo é semelhante à dessolvatação de íons, porém com energias de colisão superiores. A dissociação pode ser obtida pela aplicação de uma diferença de potencial entre componentes dessa região.
Dissociação induzida por superfície - surface-induced dissociation (SID)

Fragmentação resultante da colisão de um íon com uma superfície.

Dissociação iônica - ionic dissociation

Dissociação de um íon em outro íon de menor massa e em uma ou mais espécies neutras ou íons com menor carga.

Dissociação por captura de elétrons - electron capture dissociation $(E C D)$

Processo no qual moléculas com múltiplas protonações interagem com elétrons de baixa energia. A captura de um elétron pelo cátion elétron-par $[\mathrm{M}+\mathrm{nH}]^{\mathrm{n}+}$ libera energia e reduz sua carga para formar o correspondente íon elétron-impar $[\mathrm{M}+\mathrm{nH}]^{(\mathrm{n}-1)+}$, o qual se dissocia prontamente.

Dissociação por transferência de elétrons - electron transfer dissociation (ETD)

Processo no qual moléculas com múltiplas protonações recebem um elétron de um ânion com afinidade eletrônica relativamente baixa. A captura de elétron libera energia e reduz sua carga para formar o correspondente íon elétron-impar $[\mathrm{M}+\mathrm{nH}]^{(\mathrm{n}-1)+}$, o qual se dissocia prontamente.

Dissociação radioativa no infravermelho por corpo negro blackbody infrared radiative dissociation (BIRD)

Caso especial da dissociação por múltiplos fótons no infravermelho, onde a excitação de um íon reagente é causada pela absorção de fótons irradiados no infravermelho a partir de regiões adjacentes com características de um corpo negro aquecido. Estas regiões normalmente são as paredes de uma câmara de vácuo.

Efeito espaço-carga - space charge effect

Resultado da repulsão mútua de partículas de mesma carga (íons, elétrons, etc.) quando espacialmente próximas. Este efeito pode causar a movimentação indesejada de íons em um feixe, sendo notado em instrumentos do tipo ion trap que confinam uma grande quantidade de íons em um pequeno espaço.

Eficiência da ionização - ionization efficiency

Razão entre o número de íons formados e o número de elétrons ou fótons utilizados ou, alternativamente, o número de moléculas consumidas na fonte de ionização.

Eficiência de transmissão - transmission efficiency

Razão entre o número de íons que saem de uma região do espectrômetro de massas e o número que íons que adentram essa região.

Ejeção axial - axial ejection

Ejeção de um íon do interior de um ion trap em uma direção paralela ao eixo longitudinal do mesmo.

Ejeção axial seletiva de íons - mass selective axial ejection

Uso da instabilidade seletiva de massas para ejeção de íons de determinada $\mathrm{m} / \mathrm{z}$ ao longo do eixo de um ion trap.

Ejeção de íons por ressonância - resonance ion ejection

Modo de ejeção de íons de um ion trap baseado na aplicação de uma tensão auxiliar de radiofrequência aos eletrodos de captura ou eletrodos auxiliares. A tensão aplicada é sintonizada à frequência de oscilação de um íon específico, o qual absorve energia por ressonância e é ejetado.

Ejeção radial - radial ejection

Ejeção de um íon de um ion trap na direção perpendicular ao eixo longitudinal do mesmo.

Eletrospray ortogonal - orthogonal electrospray

Uma configuração da fonte de ionização por eletrospray na qual o eixo do spray está em um ângulo reto em relação ao eixo do cone de amostragem (entrada da amostra no equipamento).

\section{Eletronvolt, $\mathrm{eV}$}

Unidade de energia não pertencente ao SI e de símbolo eV, definida como a energia adquirida por uma partícula contendo uma unidade de carga quando acelerada através de uma diferença de potencial de 
um volt. Um eletronvolt é igual a $1.602176487(40) \times 10^{-19} \mathrm{~J}$, onde os dígitos entre parênteses indicam a incerteza estimada nos dois últimos dígitos deste valor.

Energia de aparecimento - appearance energy

Energia mínima necessária para que um átomo ou molécula produza uma espécie (íon) detectável. Na ionização por elétrons, trata-se da energia mínima necessária para detecção de um dado fragmento. O termo anterior, potencial aparente, está em desuso.

Espectro de ganho de massa neutra constante - constant neutral mass gain spectrum

Espectro formado por todos os íons produto gerados pelo ganho de uma massa neutra específica, proveniente de reações íon/molécula com um gás em uma célula de colisão.

Espectro de íon precursor - precursor ion spectrum

Espectro de massas onde a separação de $\mathrm{m} / \mathrm{z}$ registra os íons precursores que originam íons produto selecionados.

Espectro de íons produto - product ion spectrum

Espectro de massas onde a separação de $\mathrm{m} / \mathrm{z}$ registra os íons produto resultantes de um íon precursor de $\mathrm{m} / \mathrm{z}$ selecionada.

Espectro de massas - mass spectrum

Um gráfico da abundância relativa de íons em um feixe, em função de seus valores de $\mathrm{m} / \mathrm{z}$.

Espectro de massas deconvoluído - deconvoluted mass spectrum

Espectro de massas processado com um algoritmo idealizado para extrair um determinado sinal ou sinais de dados experimentais brutos. Como exemplo, pode-se citar a determinação da massa verdadeira de um biopolímero em um espectro obtido através da ionização por eletrospray. Os diversos picos correspondentes aos diferentes números de cargas adquiridas pela molécula durante a ionização podem ser deconvoluídos para determinação de sua massa verdadeira.

Espectro de perda neutra constante - constant neutral loss spectrum

Espectro de todos os íons precursores que sofreram um decréscimo de uma determinada $m / z$, a qual corresponde à massa da espécie neutra eliminada dividida pelo número de cargas do íon precursor. Os íons produto detectados são gerados pela perda de uma massa neutra específica após dissociação induzida por colisão do íon precursor.

Espectrógrafo de massas - mass spectrograph

Um instrumento que separa um feixe de íons de acordo com seus valores de $\mathrm{m} / z$. Os íons são direcionados a um detector como uma placa fotográfica.

Espectrometria de massas - mass spectrometry

O estudo da matéria através da formação de íons em fase gasosa e sua caracterização pela massa, carga, estrutura ou propriedades físico-químicas, empregando espectrômetros de massas.

Espectrometria de massas ambiente - ambiente mass spectrometry

Técnica de espectrometria de massas que emprega a ionização ambiente para formar íons.

Espectrometria de massas de ângulo resolvido - angle resolved mass spectrometry

Técnica utilizada para investigar detalhes do processo de excitação por colisão de íons precursores. São consideradas relações entre o ângulo de desvio do íon precursor após a colisão, a energia interna transferida e as massas do íon precursor e do seu par de colisão.

Espectrometria de massas de diluição isotópica - isotope dilution mass spectrometry (IDMS)

Técnica quantitativa de espectrometria de massas na qual um composto isotopicamente enriquecido é utilizado como padrão interno.

Espectrometria de massa de íons secundários - secondary ion mass spectrometry

Técnica em que um feixe focalizado de íons primários produz íons secundários que são analisados por espectrometria de massas.
Espectrometria de massas de razão isotópica - isotope ratio mass spectrometry (IRMS)

Medida e estudo da quantidade relativa de diferentes isótopos de um elemento em um material usando espectrometria de massas.

Espectrometria de massas por aceleração - accelerator mass spectrometry

Técnica de espectrometria de massas na qual moléculas e átomos são ionizados a partir de uma amostra, acelerados a energias de $\mathrm{MeV}$ e posteriormente separados de acordo com seu momento, carga e energia, o que permite alta discriminação para medidas de abundância isotópica.

Espectrometria de massas por injeção em fluxo - flow injection mass spectrometry

Um método de análise por injeção em fluxo, na qual a amostra é introduzida em um fluxo contínuo de um líquido transportador apropriado para análise por espectrometria de massas.

Espectrometria de massas por neutralização e reionização neutralization reionization mass spectrometry (NRME)

Um procedimento pelo qual espécies neutras são formadas a partir de íons de $m / z$ selecionados pela transferência de carga para um gás de colisão ou pela dissociação. As espécies neutras são separadas dos íons remanescentes e ionizadas pela colisão com um segundo gás.

Espectrometria de massas por plasma indutivamente acoplado - inductively coupled plasma mass spectrometry (ICP-MS)

Técnica de espectrometria de massas baseada em uma fonte de íons por plasma indutivamente acoplado. Esta fonte atomiza as amostras em seus átomos constituintes e ioniza-os para formar cátions atômicos. A técnica é bastante sensível para uma série de metais e diversos não metais, provendo informação sobre a distribuição isotópica dos elementos.

Espectrometria de massas sequencial no espaço - tandem mass spectrometry in space

Procedimento de espectrometria de massas sequencial que utiliza diferentes analisadores de $\mathrm{m} / \mathrm{z}$ espacialmente (fisicamente) separados, para cada estágio de análise. Íons de $m / z$ específicas são selecionados em uma seção do equipamento, dissociados em uma região intermediária (célula de colisão) e os íons produto gerados são transmitidos para outro analisador de $m / z$ para separação e registro de dados.

Espectrometria de massas sequencial no tempo - tandem mass spectrometry in time

Procedimento de espectrometria de massas sequencial no qual o espectro de íons produto é registrado em um mesmo analisador de $m / z$ (como ion trap de Paul, ion trap linear ou espectrômetro de massas de ressonância ciclotrônica de íons), porém em intervalos de tempo distintos. Íons de uma faixa específica de $\mathrm{m} / \mathrm{z}$ são selecionados, dissociados, e os íons produto analisados sequencialmente no tempo.

Espectrometria de massas/espectrometria de massas ou espectrometria de massas sequencial - mass spectrometry/mass spectrometry, tandem mass spectrometry

Aquisição e estudo de espectros de íons produto ou precursores originados a partir de íons selecionados em um primeiro estágio de análise de massas. A espectrometria de massas sequencial pode ser realizada em instrumentos incorporando mais de um analisador (espectrometria de massas sequencial no espaço) ou em instrumentos do tipo ion trap (espectrometria de massa sequencial no tempo).

Espectrometria por mobilidade iônica (de íons) - ion mobility spectrometry (IMS)

Separação de íons de acordo com suas velocidades, através de um gás de amortecimento sob a influência de um campo elétrico.

Espectrômetro de massas - mass spectrometer

Um instrumento que mede os valores de $m / z$ e a abundância de íons em fase gasosa. 
Espectrômetro de massas com campo dinâmico - dynamic field mass spectrometer

Espectrômetro de massas no qual a separação por $\mathrm{m} / \mathrm{z}$ é obtida usando um ou mais campos elétricos, que variam com o tempo.

Espectrômetro de massas com quadrupolo de transmissão transmission quadrupole mass spectrometer

Espectrômetro de massas que consiste de um arranjo de quatro eletrodos cilíndricos, cujos centros formam os cantos de um quadrado e cujos eletrodos opostos estão conectados. A tensão aplicada entre os pares de eletrodos conectados é uma sobreposição de um potencial estático e um de radiofrequência senoidal. O movimento de um íon nas dimensões x e y é descrito pela equação de Mathieu, cujas soluções mostram que íons de determinada faixa de $\mathrm{m} / \mathrm{z}$, podem ser transmitidos ao longo do eixo $\mathrm{z}$.

Espectrômetro de massas de ressonância ciclotrônica de íons - ion cyclotron resonance mass spectrometer (ICR MS)

Espectrômetro de massas no qual os íons a serem detectados, com um determinado valor de $\mathrm{m} / \mathrm{z}$, absorvem energia através do efeito de um campo elétrico de alta frequência e de um campo magnético constante, perpendicular ao campo elétrico. O máximo de energia é absorvido pelos íons que satisfazem a condição de ressonância ciclotrônica e, como resultado, estes são separados dos íons de $\mathrm{m} / \mathrm{z}$, diferentes.

Espectrômetro de massas de ressonância ciclotrônica de íons com transformada de Fourier - Fourier transform ion cyclotron resonance mass spectrometer (FT-ICR MS)

Um detector de espectrometria de massas com base no princípio da ressonância ciclotrônica de íons, na qual um íon inserido em um campo magnético se move em uma órbita circular de frequência ciclotrônica, sendo característica ou seletiva a sua $\mathrm{m} / \mathrm{z}$. Os íons são excitados para uma órbita de maior raio, usando um pulso de campo elétrico de radiofrequência, onde sua imagem de carga é detectada em uma placa receptora de sinal no domínio do tempo. A transformação de Fourier do sinal no domínio de tempo resulta em um sinal no domínio de frequência, que é convertido em um espectro de massas com base na relação inversa entre a frequência ciclotrônica e a $\mathrm{m} / \mathrm{z}$.

Espectrômetro de massas de setor - sector mass spectrometer

Espectrômetro de massa composto por um ou mais setores magnéticos para a seleção de $\mathrm{m} / \mathrm{z}$ em um feixe de íons monoenergéticos. Tais instrumentos também podem ter um ou mais setores elétricos para a dispersão de energia que podem ser arranjados para a velocidade de focalização, compensando a dispersão pelo setor magnético, se o feixe não for verdadeiramente monoenergético. Essa combinação proporciona a dupla focalização dos íons de mesma $\mathrm{m} / \mathrm{z}$, ou seja, com respeito tanto à direção quanto à velocidade.

Espectrômetro de massas híbrido - hybrid mass spectrometer

Um espectrômetro de massas que combina analisadores de diferentes tipos para realizar espectrometria de massas sequencial. Exemplos: QTOF, IT-TOF.

Espectrômetro de massas por feixe - beam mass spectrometer Espectrômetro de massas no qual um feixe contínuo de íons é acelerado a partir da fonte de íons e transferido até um detector através de um ou mais analisadores de $\mathrm{m} / \mathrm{z}$.

Espectrômetro de massas por tempo de voo - time-of-flight mass spectrometer (TOF-MS)

Instrumento que separa íons por $\mathrm{m} / \mathrm{z}$, em uma região livre de campo após aceleração por uma voltagem de aceleração fixa. Íons com a mesma energia translacional inicial e diferente $\mathrm{m} / \mathrm{z}$ levam tempos diferentes para atravessar uma dada distância em uma região livre de campo.

Espectrômetro de massas sequencial - tandem mass spectrometer

Espectrômetro de massas desenhado para fazer espectrometria de massas/espectrometria de massas.
Espectrômetro de massas triplo-quadrupolo - triple quadrupole mass spectrometer

Espectrômetro de massas sequencial composto por dois quadrupolos de transmissão montados em série, entre os quais há um quadrupolo Rf-exclusivo que funciona como célula de colisão.

Exclusão dinâmica - dynamic exclusion

Artifício de software utilizado para evitar a seleção repetida de íons precursores durante experimentos de aquisição dependente de dados na análise de misturas complexas por cromatografia líquida acoplada à espectrometria de massas. Como resultado, íons previamente selecionados para dissociação induzida por colisão são dinamicamente excluídos da lista de íons precursores, evitando a aquisição repetida de dados.

Extração ortogonal - orthogonal extraction

Aceleração pulsada de íons perpendicularmente à sua direção original de viagem no espectrômetro de massas. Utilizada tipicamente em espectrômetros de massas com analisadores por tempo de voo.

Extração retardada - delayed extraction

Aplicação de um pulso de tensão de aceleração após um tempo pré-determinado da dessorção/ionização a partir de uma superfície. O atraso na extração dos íons permite a focalização de suas energias em um espectrômetro de massas com analisador por tempo de voo.

\section{Focalização por colisão - collisional focusing}

Efeito verificado no interior de um ion trap de radiofrequência ou em um quadrupolo linear onde colisões dissipam parte da energia translacional dos íons, fazendo com que os mesmos sejam focalizados próximos ao centro do ion trap ou no eixo do quadrupolo linear. Este efeito aumenta com o aumento da pressão do gás de colisão até um ponto onde a perda dos íons por espalhamento se torna o processo dominante.

Focalização por retardo de tempo - time-lag focusing (TLF)

Focalização da energia de íons formados na fase gasosa em um espectrômetro de massas por tempo de voo, realizada pela introdução de um intervalo de tempo entre a formação dos íons e a aplicação do pulso de voltagem aceleradora.

Fonte de íons (ionização) - ion source

Região do espectrômetro de massas onde são produzidos íons na fase gasosa.

\section{Fotodissociação - photodissociation}

Processo onde o íon ou molécula reagente se dissocia como resultado da absorção de um ou mais fótons.

Fotoionização - photoionization

A ionização de um átomo ou molécula por um fóton, descrito por $\mathrm{M}+h \mathrm{v} \rightarrow \mathrm{M}^{+\cdot}+\mathrm{e}$.

Fotoionização à pressão atmosférica - atmospheric pressure photoionization (APPI)

Ionização química à pressão atmosférica na qual os íons reagentes são gerados por fotoionização.

Fragmentação distante da carga - charge remote fragmentation

Fragmentação de um íon no qual a ligação rompida está isolada do sítio de carga aparente pela distância de várias ligações químicas.

Fragmentação induzida por carga - charge-mediated fragmentation

Fragmentação de um íon no qual a ligação rompida é adjacente ao sítio de carga aparente e envolve o movimento de um par de elétrons desta ligação para o sítio de carga original. Como consequência, têmse a migração da carga para o átomo adjacente.

Fragmento interno - internal fragment

Íon fragmento de um íon peptídico precursor formado pela clivagem simultânea de duas ligações na cadeia principal. Ocorre normalmente pela combinação de fragmentações do tipo b e y ou, ocasionalmente, pela combinação de fragmentações do tipo a e y. 
Funil de íons - ion funnel

Arranjo em série de eletrodos circulares (anéis) com diminuição progressiva de seu diâmetro interno. A aplicação de potenciais de radiofrequência e voltagens fixas resulta na focalização dos íons ao longo do eixo central do arranjo.

Gás auxiliar - auxiliary gas

Um gás empregado em uma fonte de spray em conjunto ao gás de nebulização para auxiliar na remoção do solvente.

Gás de amortecimento - buffer gas, bath gas

Gás inerte utilizado para reduzir, por meio de colisões, a energia interna ou translacional de íons.

Gás de bainha - sheath gas

Gás introduzido por um tubo circundante coaxial ao capilar de eletrospray para auxiliar na nebulização de solvente e formação de gotículas.

Gás de colisão - collision gas

Gás inerte usado para ativação colisional ou um gás reativo utilizado para reações íon/molécula.

Gás de contracorrente - countercurrent gas

Um fluxo de gás inerte, geralmente aquecido, utilizado em electrospray e outras fontes de ionização baseadas em nebulização, para auxiliar na evaporação do solvente nebulizado. O fluxo do gás tem sentido oposto ao da nebulização.

Gás reagente - reagent gas

Gás que reage com íons e produz íons produto através de reações íon/molécula. Por exemplo, o metano usado em ionização química ou gases utilizados em câmaras de colisão em experimentos de reação íon/molécula.

Gás secante - drying gas

Gás inerte utilizado para promover a remoção de solvente de gotículas produzidas em métodos de ionização por nebulização.

Geometria direta - forward geometry, normal geometry

Configuração de um espectrômetro de massas de dupla focalização, no qual o feixe de íons atravessa o setor elétrico antes do setor magnético.

Geometria reversa - reverse geometry

Configuração de um espectrômetro de massas de dupla focalização, no qual o feixe de íons atravessa o setor magnético antes do setor elétrico.

Imageamento por espectrometria de massas - imaging mass spectrometry

Procedimento empregado para formar imagens quimicamente seletivas de um objeto com base na detecção de íons dessorvidos de sua superfície.

Impressão digital de massas peptídicas - peptide mass fingerprinting $(P M F)$

Um método para análise de proteínas, onde uma proteína desconhecida é química ou enzimaticamente clivada em fragmentos peptídicos, cujas massas são determinadas por espectrometria de massas. As massas desses peptídeos são comparadas às massas de peptídeos calculadas a partir proteínas conhecidas em um banco de dados e analisadas estatisticamente para determinar a melhor correlação.

Incremento de ionização - ionization (ion) enhancement

Fenômeno onde a eficiência de ionização de um composto é aumentada pela presença de um composto diferente.

Infusão direta - direct infusion

Um método de introdução de amostra em fase líquida no qual a mesma é bombeada a uma vazão contínua para o espectrômetro de massas. (MSI)

Instabilidade seletiva de massas - mass selective instability

Combinação apropriada de campos elétricos oscilantes aplicados a um ion trap que resulta em trajetórias instáveis para íons de uma determinada faixa de $m / z$ e, consequentemente, na ejeção dos mesmos.

Intensidade relativa (ao pico base) - relative intensity (to the base peak)

Razão entre a intensidade de um pico no espectro de massas e a intensidade do pico base (pico de maior intensidade no espectro). Esta relação é geralmente normalizada, considerando-se o pico base como $100 \%$.

Íon - ion

Uma espécie atômica, molecular ou radicalar que possui carga elétrica.

\section{Íon a - a-ion}

Íon fragmento contendo a porção N-terminal de um peptídeo, formado pela cisão da ligação C-C da cadeia peptídica principal do íon precursor.

Íon acílio - acylium ion

Íon com número par de elétrons em sua camada de valência (íon de elétron par; camada fechada) cuja fórmula geral é $\mathrm{RC} \mathrm{O}^{+}$(e sua possível forma de ressonância $\mathrm{RC}^{+}=\mathrm{O}$ ).

Íon aduto - adduct ion

Íon formado pela associação de um íon com um ou mais átomos ou moléculas, formando assim um íon contendo todos os átomos do íon precursor e todos os átomos pertencentes aos átomos ou moléculas associadas.

Íon $\mathbf{b}$ - $b$-ion

Íon fragmento contendo a porção N-terminal de um peptídeo, formado pela cisão da ligação C-N da cadeia peptídica principal do íon precursor.

Íon c-c-ion

Íon fragmento contendo a porção N-terminal de um peptídeo, formado pela cisão da ligação N-C da cadeia peptídica principal do íon precursor.

\section{Íon carbênio - carbenium ion}

Íon de camada fechada (elétron par) hipovalente onde a carga formal está localizada sobre um átomo de carbono, cuja fórmula geral pode ser escrita como $R^{1} R^{2} R^{3} C^{+}$, onde $R$ pode representar qualquer estrutura orgânica.

Nota: Previamente referido como íon carbônio. As duas denominações são coletivamente chamadas de carbocátion.

Íon carbônio - carbonium ion

Íon de camada fechada (elétron par) hipervalente onde a carga recai sobre um átomo de carbono contendo uma quinta ligação covalente, como em $\mathrm{H}_{5} \mathrm{C}^{+}$, o íon reagente mais abundante quando metano é utilizado como gás reagente em ionização química.

Nota: este termo descrevia previamente íons atualmente descritos como íons carbênio.

Íon de elétron par - even-electron ion

Um íon de camada fechada, que não contem elétrons desemparelhados em seu estado eletrônico fundamental.

Íon de referência - reference ion

Íon estável cuja estrutura ou fórmula elementar é conhecida. Esses íons são formados pela ionização direta de uma molécula com uma estrutura ou a fórmula elementar conhecida, e são utilizados para verificar, por comparação, a estrutura ou termoquímica de um íon desconhecido ou para calibrar a escala de $\mathrm{m} / \mathrm{z}$ do espectrômetro de massa.

Íon dimérico ou dímero - dimeric ion

Um íon formado pela ionização de um dímero ou pela associação de um íon com sua forma neutra como, por exemplo, [2M $]^{+*}$, $[2 \mathrm{M}+\mathrm{H}]^{+}$ou $[2 \mathrm{M}-\mathrm{H}]^{-}$.

Íon distônico - distonic ion

Íon radical cuja carga e sítio radical não estão localizados no mesmo átomo, nem em conjugação um com o outro. Por exemplo, ${ }^{\circ} \mathrm{CH}_{2}-\mathrm{OH}_{2}{ }^{+}$é um íon distônico, enquanto que o cátion radical do metanol $\mathrm{CH}_{3} \mathrm{OH}^{+}$é um cátion radical convencional. 
Íon estável - stable ion

Íon com energia interna suficientemente baixa para que não sofra rearranjo ou dissociação antes da detecção em um espectrômetro de massas.

\section{Íon fragmento - fragment ion}

Um íon produto que resulta da dissociação de um íon precursor. Íon imínio - iminium ion

Cátion com a estrutura $\mathrm{R}_{1} \mathrm{C}=\mathrm{N}^{+} \mathrm{R}_{2}$. $\mathrm{O}$ termo sinônimo íon imônio é irregular e não deve ser utilizado.

Íon isotópico - isotopic ion

Qualquer íon contendo um ou mais átomos dos isótopos naturais menos abundantes dos elementos constituintes deste íon como, por exemplo, $\mathrm{CH}_{2} \mathrm{D}^{+}$.

Íon isotopicamente enriquecido - isotopically enriched ion

Íon enriquecido com um isótopo específico, de maneira que sua abundância no íon seja superior a sua abundância natural.

Íon metaestável - metastable ion

Um íon formado com energia interna superior ao limiar para dissociação, porém com uma vida útil suficientemente alta para permitir sua saída da fonte de íons e entrada no analisador de massa, onde se dissocia antes de sua detecção.

Íon molecular - molecular ion

Um íon formado pela remoção de um ou mais elétrons de uma molécula, formando um íon positivo, ou pela adição de um ou mais elétrons a uma molécula, formando um íon negativo.

Nota: os termos íon pseudomolecular e íon quasi-molecular estão em desuso. O termo íon molecular é reservado para a molécula intacta ionizada sem adição ou retirada de um componente, somente de elétrons. Dessa forma, $[\mathrm{M}+\mathrm{H}]^{+}$não é um íon molecular.

Íon negativo - negative ion

Uma espécie atômica ou molecular que possui carga elétrica negativa.

Íon positivo - positive ion

Espécies atômicas ou moleculares que possuem uma carga elétrica líquida positiva.

Íon precursor - precursor ion

Íon que reage para formar íons produto particulares ou perdas neutras específicas. A reação pode ser de diferentes tipos, incluindo dissociação unimolecular, reação íon/molécula, isomerização, ou mudança no estado da carga.

Íon produto - product ion

Íon formado como produto de uma reação envolvendo um íon precursor particular. A reação pode ser de diferentes tipos, incluindo dissociação unimolecular para formar fragmentos iônicos, uma reação íon/molécula, ou simplesmente envolvendo uma alteração no número de cargas.

Íon radicalar - radicalar ion, odd-electron ion

Cátion ou ânion contendo elétrons desemparelhados em seu estado fundamental. O elétron desemparelhado é representado por um ponto precedido do símbolo para carga, ambos sobrescritos, como para o íon molecular de uma molécula, isto é, $\mathrm{M}^{+\bullet}$. Íons radicalares com mais de uma carga ou mais de um elétron desemparelhado são representados como $\mathrm{M}^{(2+)(2 \bullet)}$, por exemplo.

Nota: A não ser que a posição do elétron desemparelhado ou da carga possa ser associada com algum átomo específico, o símbolo da carga deve ser colocado antes do símbolo do radical.

Íon reagente - reagent ion

Um íon que reage com uma molécula neutra para produzir uma forma ionizada da molécula através de uma reação íon/molécula, por exemplo, como em uma ionização química.

Íon rearranjado - rearrangement ion

Um íon no qual os átomos ou grupos de átomos foram transferidos de uma porção da molécula ou fração molecular para outra, durante os processos de ionização e fragmentação subsequentes.

Íon tropílio - tropylium ion

Íon carbênio deslocalizado, ciclo-heptatrienílio $-\mathrm{C}_{7} \mathrm{H}_{7}^{+}$, formado pela abstração de um hidreto de um grupo $\mathrm{CH}_{2}$ do ciclo-hepta-1,3,5trieno e seus derivados.

Íon $\mathbf{x}-x$-ion

Íon fragmento contendo a porção C-terminal de um peptídeo formado pela dissociação do íon peptídeo na ligação C-C da cadeia principal.

Íon $\mathbf{y}-y$-ion

Íon fragmento contendo a porção C-terminal de um peptídeo formado pela dissociação do íon peptídeo na ligação C-N da cadeia principal.

Íon $\mathbf{z}-z$-ion

Íon fragmento contendo a porção C-terminal de um peptídeo formado pela dissociação do íon peptídeo na ligação N-C da cadeia principal.

Ionização à pressão atmosférica - atmospheric pressure ionization

Termo geral que define um processo de ionização no qual íons são formados a partir de átomos ou moléculas em condições de pressão atmosférica. Este termo não é sinônimo de ionização química à pressão atmosférica (APCI).

Ionização adiabática - adiabatic ionization

Processo pelo qual um elétron é removido de um átomo, íon, ou molécula em seu estado fundamental (mais baixa energia), produzindo assim um íon em seu estado de menor energia.

Ionização ambiente - ambiente ionization

Formação de íons, em ambiente externo ao espectrômetro de massas, a partir de amostras em seu estado nativo, com preparação mínima ou nenhuma dessa amostra.

Nota: o termo Análise direta em tempo real (DART) deve ser empregado apenas para descrever o produto comercial.

Ionização associativa - associative ionization

Processo de ionização pelo qual dois átomos ou moléculas, onde um ou ambos estão em um estado excitado, reagem para formar um único íon positivo e um elétron.

Ionização branda - soft ionization

Formação de íons em fase gasosa sem fragmentação extensiva.

Ionização de dessorção por eletrospray - desorption electrospray ionization (DESI)

Formação de íons a partir de uma amostra sólida ou líquida, à pressão atmosférica, por meio da interação de gotículas nebulizadas por eletrospray com a superfície da amostra.

Ionização de Penning - Penning ionization

Ionização que ocorre através da interação de duas ou mais espécies neutras na fase gasosa, sendo que pelo menos uma delas é internamente excitada a um estado metaestável, como um alto estado de Rydberg.

Nota: A ionização de Penning difere da ionização química, uma vez que não envolve nenhuma mudança química.

Ionização/dessorção a laser assistida por matriz à pressão atmosférica - atmospheric pressure matrix-assisted laser desorption/ ionization (AP MALDI)

Ionização/dessorção a laser assistida por matriz, na qual a amostra alvo está em condições de pressão atmosférica.

Ionização/dessorção a laser assistida por matriz em aerossol - aerosol matrix-assisted laser desorption ionization

Variação de MALDI na qual uma mistura de matriz e analito é nebulizada, originando partículas que são irradiadas com laser para produzir íons.

Ionização eletroidrodinâmica - electrohydrodynamic ionization Processo de ionização que produz gotículas carregadas eletrica- 
mente e íons a partir de um líquido sob vácuo, por meio da aplicação de um campo elétrico.

Ionização em barreira dielétrica - dielectric barrier charge ionization

Espécie de ionização química à pressão atmosférica onde o plasma ionizante não é gerado por descarga corona e sim, por um dispositivo composto por dois eletrodos contendo uma barreira dielétrica para separá-los do plasma ionizante.

Ionização forte, drástica ou dura - hard ionization

Formação de íons em fase gasosa acompanhada por extensiva fragmentação.

Ionização por bombardeamento de átomos rápidos - fast atom bombardment ionization (FAB)

Ionização de qualquer espécie pela interação de um feixe focalizado de átomos neutros, que têm uma energia translacional de vários $\mathrm{keV}$, com uma amostra normalmente dissolvida em uma matriz.

Ionização por campo - field ionization

Remoção de elétrons de qualquer espécie pela interação com um alto campo elétrico.

Ionização por captura de elétrons - electron capture ionization Ionização de um átomo ou molécula em fase gasosa pela adição de um elétron livre para formar íons $\mathrm{M}^{-}$.

Ionização por descarga luminescente - glow discharge ionization

Formação de íons a partir de átomos ou moléculas na fase gasosa, ou a partir do vapor de uma amostra sólida, quando uma voltagem é aplicada entre dois eletrodos imersos em um ambiente com um gás inerte em baixa pressão. Esta ionização acontece no cátodo.

Ionização por dessorção - desorption ionization

Formação de íons na fase gasosa a partir da superfície de uma amostra sólida ou líquida através da sua ativação por calor, campo elétrico forte, interação com partículas ou gotículas nebulizadas ou por bombardeamento com fótons.

Ionização por dessorção sobre silício - desorption ionization on silicon (DIOS)

Ionização branda que envolve a dessorção/ionização de uma amostra depositada sobre uma superfície porosa de silício. É alternativa à dessorção/ionização a laser assistida por matriz (MALDI).

Ionização por eletrospray - electrospray ionization

Processo no qual espécies ionizadas na fase gasosa são produzidas a partir de uma solução pela formação e dessolvatação de minúsculas gotas altamente carregadas, que são resultantes da aplicação de uma diferença de potencial da ordem de $\mathrm{kV}$ entre um capilar e um contraeletrodo, sob pressão atmosférica.

Nota: Quando um gás pressurizado é usado para auxiliar na formação de um spray estável, o termo ionização por eletrospray assistida pneumaticamente é usado. O termo ionspray está em desuso.

Ionização por elétrons - electron ionization

Ionização de um átomo ou molécula por elétrons, os quais são tipicamente acelerados a energias entre 10 e $150 \mathrm{eV}$ a fim de remover um ou mais elétrons do átomo ou molécula em questão. Os termos impacto de elétrons e impacto eletrônico não são recomendados.

Ionização por faísca - spark ionization

Formação de íons a partir de um material sólido por uma descarga elétrica intermitente.

Ionização por laser - laser ionization

Formação de íons em fase gasosa a partir da interação de fótons de um laser com material sólido ou líquido, ou com átomos ou moléculas já em fase gasosa.

Ionização por multifótons - multiphoton ionization (MPI)

Fotoionização de um átomo ou molécula, na qual um ou mais fótons são absorvidos.

Ionização por spray sônico - sonicspray ionization

Um processo no qual os íons em fase gasosa são produzidos à pressão atmosférica a partir de uma solução, devido a uma distribuição de carga estatisticamente desequilibrada durante a formação das gotas no spray supersônico pneumático.

Ionização por termospray - thermospray ionization

Fonte de íons na qual um líquido atravessa um capilar aquecido para produzir um spray de gotas e vapor de solvente. Íons são formados pelo desequilíbrio estatístico de cargas nas gotas ou por um filamento aquecido.

Ionização por troca de carga - charge exchange ionization (CEI)

Interação de um íon com um átomo ou molécula, na qual a carga do íon é transferida para o ente neutro, sem dissociação das espécies.

Ionização química - chemical ionization

Formação de um novo íon na fase gasosa pela reação de espécies neutras com um íon. O processo pode envolver a transferência de um elétron, próton ou outra espécie carregada entre os reagentes.

Nota: quando a ionização química gera um íon positivo, o termo pode ser usado sem nenhuma qualificação adicional. Quando um íon negativo é gerado, deve-se usar então o termo Ionização química negativa.

Ionização química à pressão atmosférica - atmospheric pressure chemical ionization (APCI)

Ionização química de uma amostra, a qual pode ser um gás ou líquido nebulizado, usando uma descarga corona à pressão atmosférica ou um beta emissor (como ${ }^{63} \mathrm{Ni}$ ).

Ionização química negativa - negative ion chemical ionization (NICI)

Ionização química que resulta na formação de íons negativos.

Ionização química por dessorção - desorption chemical ionization

Formação de íons na fase gasosa através do rápido aquecimento e dessorção de um sólido ou de um material líquido de baixa pressão de vapor na presença de um gás reagente para ionização química.

Ionização secundária - secondary ionization

Processo no qual os íons são ejetados da superfície de uma amostra como resultado do bombardeio por feixe primário de átomos ou íons.

Ionização térmica - thermal ionization

Ionização de espécies neutras pelo contato com uma superfície à alta temperatura.

Íons análogos - analog ions

São íons isoeletrônicos como, por exemplo, os cátions acetila $\mathrm{CH}_{3}-\mathrm{CO}^{+}$e tioacetila $\mathrm{CH}_{3}-\mathrm{CS}^{+}$.

Íons isotopólogos - isotopologue ions

Íons que diferem somente pela composição isotópica de um ou mais átomos constituintes como, por exemplo, $\mathrm{CH}_{4}^{+\bullet}$ e $\mathrm{CH}_{3} \mathrm{D}^{+\bullet}$ ou ${ }^{12} \mathrm{CH}_{4}^{+\bullet} \mathrm{e}^{13} \mathrm{CH}_{4}^{+\bullet}$.

Íons isotopoméricos - isotopomeric ion

Íons isoméricos que têm o mesmo número de cada isótopo, mas que diferem em suas posições dentro do íon. Íons isotopoméricos podem ser tanto isômeros configuracionais, nos quais dois isótopos trocam de posição, como estereoisômeros.

Isóbaro - isobar

Átomos ou moléculas com a mesma massa nominal, porém com massas exatas diferentes. No caso de átomos, isto equivale a diferentes nuclídeos de mesmo número de massa.

Nota: íons isobáricos são isóbaros dotados de carga elétrica.

Lentes Brubaker - Brubaker lens; Brubaker pre-filter

Conjunto de quatro eletrodos cilíndricos curtos montados em linha com um quadrupolo de transmissão em um espectrômetro de massas. Este conjunto é excitado com uma fração da voltagem AC (corrente alternada) aplicada ao quadrupolo principal, porém sem voltagem DC (corrente contínua). Como resultado, tem-se uma focalização do feixe de íons, aumentando consideravelmente a transmissão dos mesmos em uma determinação resolução de massas. 


\section{Lock mass}

Íon de $\mathrm{m} / \mathrm{z}$ conhecida, derivado de um composto padrão introduzido simultaneamente à amostra a ser analisada, que permite a correção em tempo real de desvios de leitura de $\mathrm{m} / \mathrm{z}$, decorrentes da variação do próprio instrumento.

Marcador de afinidade enriquecido isotopicamente - isotope coded affinity tag (ICAT)

Reagentes de marcação química para quantificação relativa em proteômica, constituídos por um grupo reativo capaz de se ligar à cadeia lateral de um aminoácido definido, um espaçador enriquecido isotopicamente e um grupamento específico utilizado para o isolamento por afinidade dos peptídeos e proteínas marcados (biotina, por exemplo).

Marcador de massa exata - accurate mass tag

Um marcador de massa exata é a massa de um peptídeo tríptico determinada com exatidão suficiente para permitir sua utilização na identificação de proteínas em um experimento de LC/MS.

Marcador isobárico para quantificação relativa e absoluta isobaric tag for relative and absolute quantitation (iTRAQ)

Reagentes de marcação química (derivatização) de peptídeos para quantificação relativa ou absoluta em proteômica. A metodologia está baseada na ligação covalente de marcadores com diferentes pesos moleculares à porção $\mathrm{N}$-terminal e grupos amina de cadeias laterais de peptídeos, os quais são oriundos da digestão proteica das amostras.

Massa acurada - accurate mass

Massa de um íon de carga conhecida, determinada experimentalmente, a qual é utilizada para determinar sua composição elementar.

Nota: massa acurada e massa exata não são sinônimos. O primeiro termo refere-se à massa medida empiricamente e o outro, à massa calculada (teórica).

Massa exata - exact mass

Massa calculada para um íon ou molécula contendo um isótopo específico de cada átomo, obtida a partir das massas desses isótopos usando um grau específico de precisão e exatidão.

Nota: a massa exata é a massa calculada (teórica) e não deve ser confundida com massa acurada (empírica).

Massa média - average mass

Massa de um íon ou molécula calculada usando-se a massa atômica média de cada elemento, a qual é obtida ponderando-se a massa atômica de cada isótopo com sua abundância natural.

Massa molar - molar mass

Massa de um mol (6.022 $14179(30) \times 10^{23}$ átomos ou moléculas) de um composto.

Nota: o termo "peso molecular" não é adequado porque "peso" está relacionado à força gravitacional sobre um objeto, a qual pode variar com sua localização geográfica. Historicamente, o termo tem sido utilizado para designar a massa molar calculada a partir das massas atômicas médias dos isótopos dos elementos constituintes.

Massa monoisotópica - monoisotopic mass

Massa exata de um íon ou molécula calculada a partir da massa do isótopo de ocorrência natural mais abundante de cada elemento.

Massa nominal - nominal mass

Massa de um íon ou molécula calculada a partir da massa do isótopo natural mais abundante de cada elemento, arredondada para o valor inteiro mais próximo e multiplicada pelo número de átomos de cada elemento.

\section{Microeletrospray}

Ionização por eletrospray a uma baixa vazão de solvente, tipicamente em microlitros por minuto ou menos, onde uma bomba é utilizada.

Migração de hidrogênio - hydrogen shift

Rearranjo sigmatrópico em íons onde a quebra e formação de ligações sigma envolve átomos de hidrogênio. Esta reação se submete às regras de Woodward-Hofmann que consideram a simetria de orbitais.

Modelo de carga residual - charged residue model

Modelo teórico para a produção de macromoléculas altamente carregadas na ionização por eletrospray, onde o excesso de carga gerado nas gotículas é transferido para estas moléculas e retido por elas mesmo após a evaporação do solvente.

Modelo de evaporação do íon - ion evaporation model

Mecanismo para descrever a produção de íons na fase gasosa a partir de gotículas altamente carregadas na ionização por eletrospray. Neste modelo, os íons são diretamente ejetados da superfície da gotícula. Acredita-se que este mecanismo seja predominante para moléculas de baixa massa molar.

Molécula anionizada - anionized molecule

Íon formado pela associação de um ânion com uma molécula $\mathrm{M}$, por exemplo, $[\mathrm{M}+\mathrm{Cl}]$

Nota: Os termos íon quasi-molecular e íon pseudomolecular estão em desuso e devem ser evitados.

Molécula cationizada - cationized molecule

Íon formado pela associação de um cátion com uma molécula $\mathrm{M}$, por exemplo, $[\mathrm{M}+\mathrm{Na}]^{+}$ou $[\mathrm{M}+\mathrm{K}]^{+}$.

Molécula desprotonada - deprotonated molecule

Um íon formado pela remoção (abstração) de um próton a partir de uma molécula $\mathrm{M}$, para formar um íon representado por $[\mathrm{M}-\mathrm{H}]$.

Molécula protonada - protonated molecule

Um íon formado pela interação de uma molécula com um próton para formar um complexo representado pela descrição química $[\mathrm{M}+\mathrm{H}]^{+}$.

Nota 1. Moléculas com múltiplos prótons são representadas por $[\mathrm{M}+\mathrm{nH}]^{\mathrm{n}+}$, onde $\mathrm{n}$ é o numero de prótons.

Nota 2. Os termos íon molecular protonado, íon pseudomolecular e íon quasi-molecular não são recomendados. O termo molécula protonada, ou a descrição química como, por exemplo, $[\mathrm{M}+\mathrm{H}]^{+}$, devem ser usados.

Monitoramento consecutivo de reações - consecutive reaction monitoring

Experimento de espectrometria de massas com três ou mais estágios de separação de $m / z$, no qual os produtos de fragmentação sequencial ou reações bimoleculares são selecionados para detecção.

Monitoramento de íon selecionado - selected ion monitoring (SIM)

Operação de um espectrômetro de massas em que a abundância dos íons de um ou mais valores específicos de $\mathrm{m} / z$ é gravada, ao invés do espectro de massas total.

Monitoramento de reação selecionada - selected reaction monitoring (SRM)

Dados adquiridos somente para um ou mais íons produto específicos produzidos por íons precursores de $\mathrm{m} / \mathrm{z}$ selecionados em um estágio prévio de espectrometria de massas, ao invés da aquisição de todo o espectro de massas de íons produto. O monitoramento de reação selecionada pode ser realizado por espectrometria de massas sequencial no tempo ou por espectrometria de massas sequencial no espaço.

Monitoramento de reações múltiplas - multiple reaction monitoring (MRM)

Aplicação do monitoramento de reação selecionada para múltiplos íons produto provenientes de um ou mais íons precursores. Este termo não deve ser confundido com o monitoramento de reações consecutivas, que envolve a aplicação em série de três ou mais etapas do monitoramento de reação selecionada.

Movimento ciclotrônico - cyclotron motion

Movimento circular de uma partícula carregada de carga $q$ movendo-se a uma velocidade $v$ em um campo de fluxo magnético $B$, resultante da força de Lorentz. 
MS $^{\mathrm{n}}$ ou espectrometria de massas de múltiplos estágios multiple-stage mass spectrometry

Este símbolo refere-se a múltiplos experimentos sequenciais de espectrometria de massa, onde n é o número de estágios de análise de massa (enésima geração de íons produto).

Nanoeletrospray

Ionização por eletrospray em vazões muito baixas de solvente, tipicamente centenas de nanolitros por minuto ou menos, frequentemente sem o uso de uma bomba externa. O termo nanospray deverá apenas ser usado para descrever o produto comercialmente disponível no mercado.

Número de carga, $\mathbf{z}$ - charge number

Um número inteiro representando a carga total de um íon, não considerando o sinal, dividida pela magnitude da carga do elétron, $e$.

Número de massa, A - mass number

Soma do número de prótons e nêutrons em um átomo, molécula ou íon. Equivalente à massa nominal.

Padrão isotópico, perfil isotópico, agregado isotópico - isotope pattern, isotope cluster

Conjunto de picos relacionados a íons com a mesma fórmula molecular, porém contendo diferentes isótopos como, por exemplo, os picos de $\mathrm{m} / \mathrm{z} 16$ e 17 na amostra de $\mathrm{CH}_{4}$, que correspondem aos íons ${ }^{12} \mathrm{CH}_{4}{ }^{+} \mathrm{e}^{13} \mathrm{CH}_{4}^{+}$.

Perda neutra ou eliminação neutra - neutral loss

Eliminação de uma espécie não carregada a partir de um íon durante sua dissociação.

Pico (em espectrometria de massas) - peak

Região localizada em um espectro de massas que representa o sinal de um íon relativamente intenso.

Nota: Deve-se tomar cuidado ao distinguir os picos dos espectros de massas dos picos em métodos cromatográficos.

Pico base - base peak

Pico de maior intensidade em um espectro de massas.

Pico de massa - mass peak

Registro do sinal de um íon em uma determinada $\mathrm{m} / \mathrm{z}$.

Placa de microcanal - microchannel plate (MCP)

Uma placa fina que contém uma série de canais densamente agrupados onde cada canal atua como um dinodo multiplicador de partículas contínuo. Quando uma partícula carregada ou um fóton atinge a placa, uma cascata de elétrons secundários é criada, os quais saem pelo lado oposto da placa. Este sistema é comumente utilizado como detector em equipamentos com analisadores de massa por tempo de voo.

Plasma (em espectroquímica) - plasma (in spectrochemistry)

Um gás que está parcialmente ionizado e contém partículas de vários tipos: elétrons, átomos, íons e moléculas. O plasma como um todo é eletricamente neutro. (ICP)

Plasma indutivamente acoplado - inductively coupled plasma

Fonte de íons onde a energia necessária para a formação de um plasma gasoso é fornecida por um campo eletromagnético indutivo.

Poder de resolução (espectrometria de massa) - resolving power

A habilidade de um espectrômetro de massas em fornecer um valor específico de resolução de massas.

Nota: O procedimento pelo qual $\Delta m / z$ foi obtido e os valores de $\mathrm{m} / \mathrm{z}$ em que a medição foi realizada devem ser comunicados.

Proteômica shotgun - shotgun proteomics

Identificação de proteína usando uma combinação de cromatografia líquida de alta eficiência e espectrometria de massas em que as proteínas presentes na mistura são digeridas e os peptídeos resultantes são separados por cromatografia líquida e identificados por espectrometria de massas.

Proteômica do tipo bottom-up - bottom-up proteomics

Método de identificação de proteínas baseado na digestão pro- teolítica das amostras antes da análise por cromatografia líquida e espectrometria de massas. As proteínas podem ser isoladas por eletroforese em gel antes da digestão ou, nos casos de proteômica do tipo shotgun, digeridas diretamente em uma mistura complexa para análise dos peptídeos resultantes.

Quadruplo de colisão - collision quadrupole

Quadrupolo de transmissão no qual um potencial oscilante de radiofrequência é aplicado, de maneira a focalizar um feixe de íons através de um gás de colisão. Não há separação de $\mathrm{m} / \mathrm{z}$.

Nota: outros arranjos multipolares de maior ordem, como hexapolos e octapolos, também podem ser utilizados desta maneira.

Quadrupolo RF-exclusivo - $R F$-only quadrupole

Dispositivo quadrupolo de transmissão no qual uma tensão de radiofrequência sinusoidal (RF) é aplicada entre os pares conectados de hastes opostas em um quadrupolo linear, fornecendo um dispositivo de transmissão para todos os íons com valores de $\mathrm{m} / \mathrm{z}$ acima de um valor de corte.

Nota: multipolos de ordem superior, como hexapolos, também podem ser usados dessa maneira.

Quantificação absoluta de proteínas - absolute quantitation of proteins (AQUA)

Método para a quantificação absoluta de proteínas em espectrometria de massas por meio da quantificação de seus peptídeos proteolíticos característicos, usando peptídeos sintéticos marcados isotopicamente como padrões internos.

Quantificação livre de marcadores - label-free quantitation

Um método para determinar a concentração de proteínas sem a utilização de marcadores com isótopos estáveis, por meio da combinação de digestão proteica e LC/MS. A quantificação da proteína pode ser realizada de duas formas: através da medida da intensidade de sinal dos íons de peptídeos correspondentes a esta proteína, ou, por contagem e comparação do número de espectros de massas de fragmentação dos peptídeos que identificam uma determinada proteína.

Reação associativa íon/molécula - associative ion/molecule reaction; association reaction

Reação onde um íon e uma espécie neutra se combinam para formar um único íon.

Reação de fragmentação - fragmentation reaction

Reação de um íon que resulta na formação de dois ou mais fragmentos, onde pelo menos um destes é um íon.

Reação de inversão de carga - charge inversion reaction

Reação de um íon com uma espécie neutra, superfície ou íon de polaridade oposta, na qual a carga do íon produto é inversa ao sinal da carga do íon reagente.

Reação de transferência de carga - charge transfer reaction

Reação de um íon com uma espécie neutra, onde parte ou toda a carga do íon reagente é transferida para a espécie neutra.

Reação de transferência parcial de carga - partial charge transfer reaction

Reação de um íon com uma espécie neutra na qual uma porção da carga do íon é transferida para o neutro.

Reação induzida por superfície - surface-induced reaction (SIR)

Processo no qual um íon reagente interage com uma superfície para produzir ou uma espécie quimicamente diferente ou uma alteração na sua energia interna.

Reação íon/espécie neutra - ion/neutral species reaction

Processo no qual uma espécie dotada de carga interage com um reagente neutro, produzindo uma espécie quimicamente diferente ou promovendo variação na energia interna de um ou ambos os reagentes.

Reação íon/molécula - ion/molecule reaction

Reação entre um íon e uma espécie neutra, onde a espécie neutra é uma molécula.

Nota: A forma hifenada deste termo, reação íon-molécula, é 
obsoleta. O termo hifenado sugere uma reação onde a espécie é tanto um íon como uma molécula, o que não é apropriado.

Reação retro Diels-Alder - retro Diels-Alder reaction

Mecanismo de fragmentação de íons no qual um íon positivo de um alceno cíclico se fragmenta para formar um dieno neutro e um cátion radical alceno ou um cátion radical dieno e um alceno. A reação é o inverso da reação de Diels-Alder da síntese orgânica.

Rearranjo de McLafferty - McLafferty rearrangement

Reação de rearranjo envolvendo a transferência de um átomo de hidrogênio para o sítio formal da carga ou radical via um estado de transição de seis membros, a partir de um átomo de carbono distante do sítio da carga/radical por quatro átomos (carbono gama); o subsequente rearranjo da densidade eletrônica pode proporcionar a expulsão de uma olefina.

Nota: Originalmente aplicada para íons cetona, onde o sítio carga/ radical é um oxigênio da carbonila.

\section{Refletor - reflectron}

Componente de um espectrômetro de massa por tempo de voo que usa um campo elétrico estático para inverter o sentido da viagem dos íons e aprimora a resolução de massas, assegurando que os íons de mesma $\mathrm{m} / \mathrm{z}$, mas com energias cinéticas diferentes, cheguem ao detector ao mesmo tempo.

Regra do elétron par - even-electron rule

Regra que afirma que íons de elétron par (camada fechada) geralmente formam fragmentos de elétron par (camada fechada). Em contraste, íons de elétron ímpar (camada aberta) podem se dissociar para formar tanto fragmentos de elétron par (Regra do elétron ímpar) como de elétron ímpar.

Regra do nitrogênio - nitrogen rule

Regra que determina que uma molécula orgânica neutra contendo um ou mais átomos dos elementos $\mathrm{C}, \mathrm{H}, \mathrm{O}, \mathrm{P}, \mathrm{S}$ ou qualquer halogênio possui uma massa nominal ímpar quando contiver um número ímpar de átomos de nitrogênio em sua estrutura.

\section{Relação massa/carga - $\mathrm{m} / \mathrm{z}$}

Unidade adimensional formada pela divisão da massa de um íon (em unidade de massa atômica unificada) pelo seu número de carga (independente do sinal). O símbolo é escrito em itálico, letras minúsculas e sem espaços.

Nota 1: o termo razão massa-carga está em desuso. A razão massa-carga tem sido utilizada no eixo horizontal de espectros de massa, embora a quantidade medida não seja exatamente a massa do íon dividida pela sua carga elétrica. Para a variável independente representada no eixo horizontal de um espectro de massas, a quantidade adimensional $\mathrm{m} / \mathrm{z}$ é recomendada.

Nota 2: O símbolo $\mathrm{m} / \mathrm{z}$ não deve ser usado como uma variável em uma equação matemática. Ao invés disto, as variáveis m e q devem ser usadas para designar massa e carga, respectivamente.

Nota 3: O sinal de igualdade não deve ser usado para designar um valor de $m / z$ como, por exemplo, $m / z=100$. O correto é usar $m / z 100$.

Nota 4: A unidade Thomson (Th) está em desuso.

Resolução ou resolução de massas (espectrometria de massas) - resolution, mass resolution

Em um espectro de massas, o valor de $\mathrm{m} / \mathrm{z}$ observado dividido pela menor diferença de $\mathrm{m} / \mathrm{z}$ para dois íons que podem ser separados: $m / z /(\Delta m / z)$.

Nota 1: O valor de $\mathrm{m} / z$ utilizado para a medição deve ser comunicado.

Nota 2: A definição e o método de medição de $\Delta m / z$ devem ser notificados. Normalmente isso é feito usando-se a largura do pico em um determinado percentual da altura do pico.

Nota 3: Alternativamente, $\Delta m / z$ é definido como a separação entre dois picos adjacentes de igual magnitude, de maneira que o vale entre eles seja uma fração determinada da altura do pico.
Resolução: definição da largura dos picos - resolution: peak width definition

Em um espectro de massas, para um pico correspondente a íons de carga unitária e de massa $\mathrm{m}$, a resolução pode ser expressa como $\mathrm{m} / \Delta \mathrm{m}$, onde $\Delta \mathrm{m}$ é a largura do pico a uma altura que é uma fração determinada da altura máxima do pico. Recomenda-se que seja utilizado um dos valores de 50,5 ou $0,5 \%$. Um padrão comum é a definição de resolução com $\Delta \mathrm{m}$ à largura total do pico na metade de sua altura máxima (full width of the peak at half its maximum height, FWHM).

Resolução: definição de 10 por cento do vale - resolution: 10 percent valley definition

$\mathrm{O}$ valor de $\mathrm{m} / \Delta \mathrm{m}$ medido para dois picos de altura igual em um espectro de massas com massas $\mathrm{m}$ e $\mathrm{m}-\Delta \mathrm{m}$, separados por um vale cujo ponto mais baixo é igual a $10 \%$ da altura de cada pico.

\section{Retardamento de pico - peak parking}

Método utilizado para prolongar o tempo que um pico cromatográfico está disponível para análise por espectrometria de massas. A vazão de fase móvel é diminuída e mantida a valores baixos enquanto o composto de interesse deixa a coluna cromatográfica, aumentandose a largura da banda de eluição de maneira a prolongar o tempo disponível para análise de massas.

Setor magnético - magnetic sector

Dispositivo que produz um campo magnético perpendicular a um feixe de partículas carregadas eletricamente. Este campo desvia o feixe de forma proporcional à relação entre o momento e a carga das partículas. Para um feixe de partículas de mesma energia, o desvio de trajetória é proporcional a $\mathrm{m} / \mathrm{z}$.

\section{Skimmer}

Cone com um orifício central que intercepta o centro de uma expansão de spray ou jato para amostrar a porção central da expansão.

Sonda de inserção direta - direct insertion probe

Aparato para introduzir uma amostra sólida ou líquida na fonte de íons do espectrômetro de massa. A amostra é usualmente depositada em um material quimicamente inerte, como o quartzo.

Supressão de ionização - ion supression

Fenômeno onde a eficiência de ionização de um composto é diminuída pela presença de um composto diferente. Este efeito é mais comumente observado na ionização por eletrospray.

Tecnologia multidimensional para identificação de proteínas - multidimensional protein identification technology (MudPIT)

Variante da proteômica do tipo shotgun, na qual proteínas são primeiramente digeridas e depois separadas por uma combinação de cromatografia líquida de troca catiônica forte e de fase reversa, seguida de detecção por espectrometria de massas.

Tempo do ciclo de varredura - scan cycle time

Tempo necessário para se obter um espectro de massas ou outras quantidades de dados de espectrometria de massas em uma separação acoplada à espectrometria de massa.

Unidade de massa atômica unificada, $\boldsymbol{u}$ - unified atomic mass unit, $u$

Unidade de massa não pertencente ao SI, definida como 1/12 da massa de um átomo de ${ }^{12} \mathrm{C}$ em repouso e em seu estado fundamental. Equivale a $1.660538782(83) \times 10^{-27} \mathrm{~kg}$. O número entre parênteses representa a incerteza estimada para os dígitos finais do valor. $\mathrm{O}$ termo unidade de massa atômica (u.m.a) é obsoleto.

Varredura de campo magnético - magnetic field (B) scan

Método para produzir um espectro de massa (de momento), variando-se a força do campo magnético em um espectrômetro de massas em setor.

Varredura de perda neutra - neutral loss scan

Varredura utilizada para gerar um espectro de massas de perda neutra constante. 


\section{AGRADECIMENTOS}

À Sociedade Brasileira de Química (SBQ), Sociedade Brasileira de Espectrometria de Massas (BrMass) e Sociedade Internacional de Espectrometria de Massas pelo incentivo à realização desse material didático. À Organização das Nações Unidas pela iniciativa da realização do Ano Internacional da Química. Ao Prof. M. N. Eberlin pelo estímulo e por suas contribuições a esse trabalho.

\section{REFERENCIAS}

1. Murray, K. M.; Boyd, R. K.; Eberlin, M. N.; Langley, G.J.; Li, L.; Naito, Y.; Standard definitions of terms relating to mass spectrometry, IUPAC; http://mass-spec.lsu.edu/msterms/index.php/Main_Page, acessada em Fevereiro 2011.

2. IUPAC Gold Book; http://goldbook.iupac.org/, acessada em Agosto 2011.

3. National Institute of Standards and Technology - NIST; http://webbook. nist.gov/chemistry/, acessada em Agosto 2011.
4. Turecek, F.; McLafferty, F. W.; Interpretation of mass spectra, University Science Books: Sausalito, 1993.

5. Niessen, W. M. A. Em The Encyclopedia of Mass Spectrometry; Gross, M. L.; Caprioli, R. M., eds.; Elsevier: Oxford, 2006.

6. Price, P.; J. Am. Soc. Mass Spectrom. 1991, 2, 336.

7. http://www.asms.org/, acessada em Agosto 2011.

8. Sparkman. O. D.;m Mass Spectrometry Desk Reference, Global View Publishing: Pittsburgh, 2006.

9. Mallet, A. I.; Down. S.; Dictionary of Mass Spectrometry, John Wiley \& Sons, Ltd: Chichester, 2010.

10. Cole, R. B., ed.; Electrospray and MALDI Mass Spectrometry: Fundamentals, Instrumentation, Practicalities, and Biological Applications, $2^{\text {nd }}$ ed., John Wiley \& Sons, Inc.: New Jersey, 2010.

11. Watson, J. T.; Sparkman, O. D.; Introduction to Mass Spectrometry: Instrumentation, Applications, and Strategies for Data Interpretation, Wiley: New York, 2007. 